\title{
PERKEMBANGAN EKONOMI KREATIF DALAM MENOPANG PEREKONOMIAN RAKYAT DI MASA PANDEMI COVID 19 (Studi Kualitatif Di 5 Penerbitan Independen)
}

\author{
DJIHADUL MUBAROK ${ }^{1}$, EVA FAUZIANA ${ }^{2}$ \\ djihadulmubarok@ibm.ac.id', evafauziana@ibm.ac.id ${ }^{2}$
}

\section{Program Studi Ekonomi Pembangunan ${ }^{1}$ Program Studi Manajemen $^{2}$ Institut Bisnis Muhammadiyah Bekasi}

\begin{abstract}
ABSTRAK
Ekonomi kreatif menjadi primadona alias bertahan dan meningkat di masa pandemi covid 19. Beberapa sektor di industri yang mengutamakan kreativitas dan seni ini meningkat permintaannya. Contohnya adalah usaha penerbitan buku independen, meski masih berskala usaha mikro, kecil dan menengah, usaha penerbitan buku lewat jalur independen ini makin diminati oleh para penulis untuk menerbitkan buku mereka di penerbit berskala UMKM ini. Di satu sisi, para pembaca pun meramaikan e-book alias makin menggemari membaca buku lewat aplikasi daring. Berbanding terbalik dengan perkembangan penerbitan independen ini, beberapa penerbit mayor yang memiliki jaringan retail di seluruh Indonesia, terpaksa harus menonaktifkan gerai mereka di masa pandemi, karena adanya kebijakan PSBB. Karena itu, penelitian ini menitikberatkan pada bagaimana ekonomi kreatif, dalam hal ini penerbitan independen, mampu menopang ekonomi rakyat di masa pandemi.
\end{abstract}

Kata Kunci: Ekonomi Kreatif, UMKM, Penerbit Independen

\section{ABSTRACT}

The creative economy becomes the major survivor and its growth increased during the COVID19 pandemic. Several sectors in the industry that prioritize creativity and art are increasing in demand. An example is the independent book publishing business, although it is still a micro, small and medium scale business, the business of publishing books through independent channels is increasingly in demand by writers to publish their books in this UMKM scale publisher. On the one hand, readers are also enlivening e-books, aka more and more fond of reading books through online applications. In contrast to the development of this independent publication, several major publishers with retail networks throughout Indonesia were forced to deactivate their outlets during the pandemic, due to the PSBB policy. Therefore, this research focuses on how the creative economy, in this case independent publishing, is able to support the people's economy during the pandemic.

Keywords: Creative Economy, Small and Medium Enterprises, Independent Publisher 


\section{PENDAHULUAN}

\section{Latar Belakang}

Sejak masa pandemi Covid 19 yang mewabah di Indonesia per-Maret 2020 lalu, beberapa sektor usaha terdampak dan mengalami kemunduran hingga kebangkrutan karena daya beli konsumen yang rendah, dan belanja masyarakat hanya difokuskan pada kebutuhan pokok saja.

Berikut daftar sektor industri yang bertahan, sulit berkembang (bangkrut) atau malah meningkat sejak adanya pandemic Covid 19:

\section{Gambar 1}

Perkembangan Dunia Usaha Di Tengah Pandemi Corona

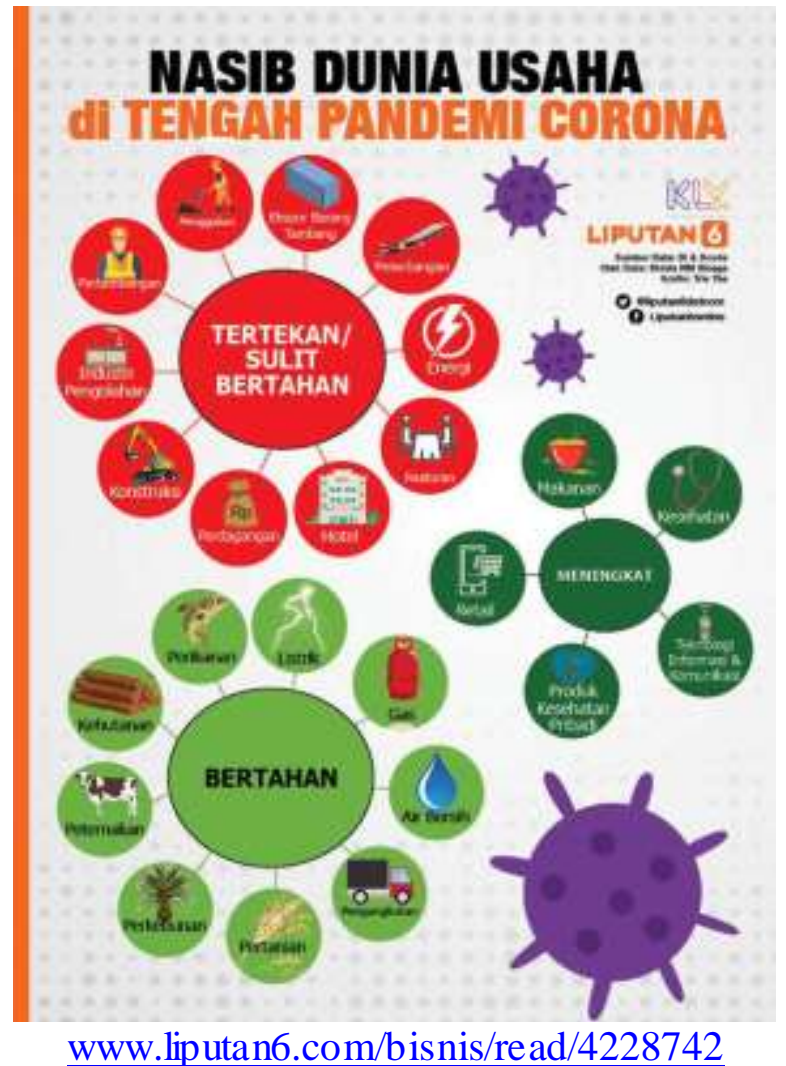


Dari gambar 1 di atas, terlihat bahwa sektor retail, makanan, kesehatan, teknologi informasi dan komunikasi, serta produk kesehatan pribadi, malah mengalami peningkatan omset selama masa pandemi Covid 19.

Dari kondisi tersebut, penulis tertarik meneliti sektor industri yang bertahan di masa pandemi, yaitu sektor penerbitan buku independen, di mana dalam industri ini, terjadi penggabungan usaha retail serta teknologi informasi dan komunikasi. Yang menarik untuk disimak, dunia penerbitan independen ini tadinya merupakan pemain baru dan tidak diperhitungkan di industri penerbitan berskala besar, atau dalam hal ini biasa disebut penerbitan major, seperti Gramedia, Mizan, Republika. Tidak hanya beroplah minimal 5,000 eksemplar saat mencetak buku, penerbit mayor ini rata-rata juga memiliki jaringan retail toko buku fisik yang tersebar di seluruh Indonesia. Namun, sejak pandemi Covid 19, beberapa toko buku milik penerbit mayor ini terpaksa dinon-aktifkan sementara, karena adanya kewajiban PSBB (Pembatasan Sosial Berskala Besar) sehingga mall-mall ditutup dan otomatis pengunjung toko retail tidak ada sama sekali.

\section{Rumusan Masalah}

Dari latar belakang yang penulis kemukakan terdahulu, penulis tertarik mengurai beberapa hal sebagai berikut:

1. Bagaimana penerbitan independen bertahan di masa pandemi Covid 19?

2. Bagaimana proses produksi dan distribusi di penerbitan independen memberi andil dalam perkembangan ekonomi kerakyatan?

\section{Tujuan Penelitian}

Penelitian ini bertujuan untuk:

1. Mengetahui proses produksi dan distribusi di penerbitan independen sehingga mampu membantu perkembangan ekonomi rakyat.

2. Membuat daftar penerbit independen yang masih aktif dan produktif di masa pandemi.

3. Memberi masukan dan saran kepada pemilik penerbitan serta pemangku kepentingan terkait dukungan untuk perkembangan industri penerbitan independen.

\section{Batasan Penelitian}

Dalam penelitian ini, penulis membatasi penelitian hanya pada penerbitan independen sebagai berikut: 


\section{Tabel 1}

Daftar Penerbit Independen ber-ISBN

\begin{tabular}{|c|l|l|l|}
\hline No. & $\begin{array}{c}\text { Nama Penerbit } \\
\text { (Dalam Inisial) }\end{array}$ & \multicolumn{1}{|c|}{ Lokasi } & \multicolumn{1}{c|}{ Percetakan } \\
\hline 1. & LR & Cirebon, Jawa Barat & Ada mesin cetak sendiri \\
\hline 2. & CVI & Bekasi, Jawa Barat & Mesin cetak di sub ke percetakan lain \\
\hline 3. & JWR & Malang, Jawa Timur & Mesin cetak di sub ke percetakan lain \\
\hline 4. & KDJ & Semarang, Jawa Tengah & Mesin cetak di sub ke percetakan lain \\
\hline 5. & DP & Padang, Sumatera Barat & Mesin Cetak di sub ke percetakan lain \\
\hline
\end{tabular}

Penulis membatasi penelitian hanya pada penerbit independen di atas, dengan alasan penulis cukup mengenal baik pemilik tiap penerbitan dan data masing-masing penerbitan mudah diakses di media sosial, serta kelima penerbit tersebut sudah memiliki ISBN sendiri, dan telah beroperasi minimal dua tahun, yaitu sejak 2018.

\section{TINJAUAN PUSTAKA}

\section{Ekonomi Kreatif}

Pengertian ekonomi kreatif menuru UNCTAD. ORG adalah, ekonomi kreatif atau creative economy adalah konsep ekonomi yang sangat mengutamakan kreativitas, penggunaan ide, pengatahuan dan teknologi untuk mengembangkan ekonomikhususnya pada bidang industri kreatif. (unctad.org).

Dalam hal ini, ekonomi kreatif mengedepankan kreativitas sebagai sumber ide atau bahan baku utama dalam memproduksi barang dan jasa. Dalam Industri penerbitan independen, kreativitas tulisan dari penulis, serta kreativitas dari para gesainer grafis, menjadi penentu utama suatu karya layak terbit dan layak dijual menjadi barang konsumtif atau tidak.

\section{Ciri-Ciri Ekonomi Kreatif}

Mengutip dari buku Ekonomi Kreatif Berbasis Kearifan Lokal (2020) berikut beberapa ciri ekonomi kreatif: 
1. Memiliki Kreativitas Intelektual

Dalam hal ini, memiliki kreativitas yang layak dibuatkan hak cipta, karena keunikan dan orisinalitas dari karya tersebut.

2. Mudah Tergantikan

Meskipun mengutamakan kreativitas, karya ini selalu dapat digantikan dengan yang baru, dan dapat diadakan terus, selama penulis menulis karya dan penerbit bersedia menerbitkan karya tersebut.

3. Distribusi Langsung dan Tidak Langsung

Tulisan atau hasil karya didistribusikan langsung untuk produk buku cetak, atau didistribusikan secara tidak langsung, bila pembaca membeli karya lewat aplikasi daring, dengan cara mengunduh buku atau e-book.

4. Membutuhkan Kerjasama

Membutuhkan kerjasama yang intens antara pihak penerbit dan pemerintah, dalam hal ini kebijakan pajak buku serta penerbitan nomor buku terdaftar (ISBN). Juga, membutuhkan kerjasama intens dalam internal penerbitan, misal kerjasama antara penulis, editor dan desainer grafis.

5. Berbasis Pada Ide

Ide sangat penting dalam pengembangan ekonomi kreatif. Ide-ide baru menjadi penanda awal keberlangsungan industri ini.

6. Tidak Memiliki Batasan

Tidak ada batasan dalam penciptaan terus, karena ide tulisan ada terus, seiring dengan perkembangan penulis serta kejadian di masyarakat sehari-hari yang beragam, yang dapat dijadikan ide tulisan.

\section{Ruang Lingkup Ekonomi Kreatif}

Disinyalir (kompas.com) ada beberapa jenis industri kreatif, antara lain:
1. Periklanan,
2. Arsitektur
3. Seni
4. Kerajinan
5. Desain
6. Mode/Fashion 
7. Media (Film, Vide dan Fotografi)

8. Game online atau permainan interaktif daring

9. Seni pertunjukan

10. Penerbitan dan percetakan

11. Software

12. Riset dan pengembangan

13. Musik

14. Penyiaran

Dalam penelitian ini, penulis fokus pada poin 10, yaitu penerbitan dan percetakan.

\section{UMKM}

Dilansir dari Kementerian Koperasi, Usaha Kecil dan Menengah Republik Indoensia, UMKM merupakan singkatan dari usaha mikro, kecil dan menengah. UMKM adalah usaha ekonomi produktif yang dijalankan individu atau badan usaha berskala kecil atau menengah. Dapat disimpulkan, UMKM dilakukan oleh masyarakat ekonomi menengah ke bawah.

Tujuan dibentuk dan diberdayakan UMKM tercantum dalam undang-undang Republik Indonesia No. 20 Tahun 2008 tentang usaha mikro, kecil dan menengah pada pasal dan 5, antara lain untuk menumbuhkan struktur perekonomian nasional yang adil dan berkembang.

\section{METODOLOGI PENELITIAN}

Penelitian ini menggunakan metode kualitatif dengan menganalisis data sekunder dari media sosial masing-masing penerbit independen.

\section{PEMBAHASAN}

\section{Penerbit Mayor}

Mengutip dari bukupedia.com, penerbit mayor adalah penerbit yang menerbitkan buku dalam skala besar, minimal 5,000 eksemplar dalam sekali cetak. Ditambah lagi, penerbit mayor biasanya memiliki jaringan toko buku retail yang tersebar di seluruh Indonesia. Memiliki kantor sendiri dan mempekerjakan karyawan secara kontrak dan menetap.

\section{Penerbit Independen}

Kebalikan dari penerbit mayor, penerbit indie atau penerbit independen, adalah perusahaan penerbit yang biasanya berskala UMKM, berbadan hukum rata-rata berbasis CV dan sudah memilik ISBN sendiri. 
Penerbit independen ini biasanya tidak memilik mesin cetak sendiri, namun bekerja sama dengan perusahaan percetakan. Jarang memiliki kantor permanen, biasanya kantor di rumah pemilik, dan mempekerjakan karyawan secara freelance atau berbasis project, dan bukan karyawan kontrak bahkan karyawan tetap.

Penerbit independen bisa mencetak dalam jumlah kecil, yang disebut POD (Print On Demand) dengan oplah 1-2 eksemplar saja sekali cetak.

\section{Perkembangan Buku Sejak 2015}

Menurut data IKAPI (Ikatan Penerbit Indonesia) industri penerbitan buku terus berkembang, meski percepatannya melambat. Tahun 2015, terdapat 1,328 penerbit dengan jumlah 711 penerbit aktif dan 617 penerbit tidak aktif.

\section{Gambar 2}

Perkembangan Jumlah Penerbit

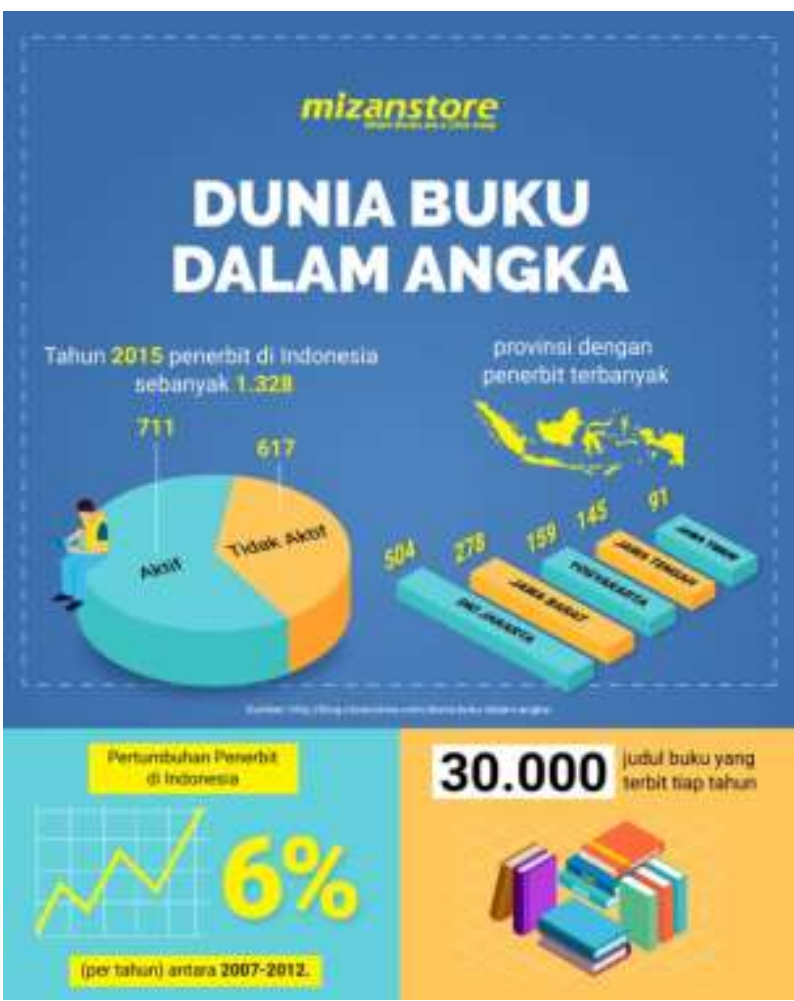

https $/ /$ blog.mizanstore.com/dunia-buku-dalam-angka 
Dari gambar di atas, dapat kita asumsikan, bahwa perkembangan penerbitan naik sekitar $6 \%$ di periode 2007 hingga 2012. Adapun penerbit berlokasi di 5 kota besar yaitu DKI Jakarta, Jawa Barat, Jawa Tengah, Jawa Timur dan Yogyakarta. Selain itu, ada sekitar 30,000 judul buku yang diterbitkan tiap tahunnya. Data tersebut belum terhitung buku-buku yang diterbitkan sendiri (self publish) atau pun buku yang terbit tidak memiliki ISBN.

\section{Perkembangan Buku di Masa Pandemi Covid 19}

Dilansir dari website IKAPI, Arys Hilman Nugraha (Direktur PT Pustaka Abadi Bangsa Republika) menyatakan bahwa, 'Penjualan buku Republika anjlok, karena selama ini distribusi melalui toko fisik konvensional, termasuk yang berjaringan seperti Gramedia (mizanstore.com).

Lebih lanjut, hasil riset IKAPI menemukan bahwa $50 \%$ penerbit mengalami penurunan produktivitas karyawan yang merosot tajam 32.7\% merosot sedang, 15.3\% merosot sedikit dan terdapat $2 \%$ penerbit yang tidak mengalami masalah dengan produktivitas karyawan mereka akibat wabah Covid-19 ini.

IKAPI juga menganalisis bahwa sebanyak $52.8 \%$ penerbit mengalami penurunan penjualan melebihi $50 \%$ dari biasanya, 29.6\% penerbit mengalami penurunan penjualan antara 31-50\% dan sebanyak $8.2 \%$ penerbit mengalami penurunan antara $10-30 \%$. Hanya sebesar $4.1 \%$ penerbit tercatat mengalami penjualan dengan kondisi relatif sama dengan kondisi sebelum pandemi Covid 19. (IKAPI.org.riset)

Dari jumlah $4.1 \%$ penerbit yang tercatat mengalami penjualan dengan kondisi relative stabil atau tidak berkurang jauh dibandingkan sebelum masa pandemi sebagai berikut antara lain: 


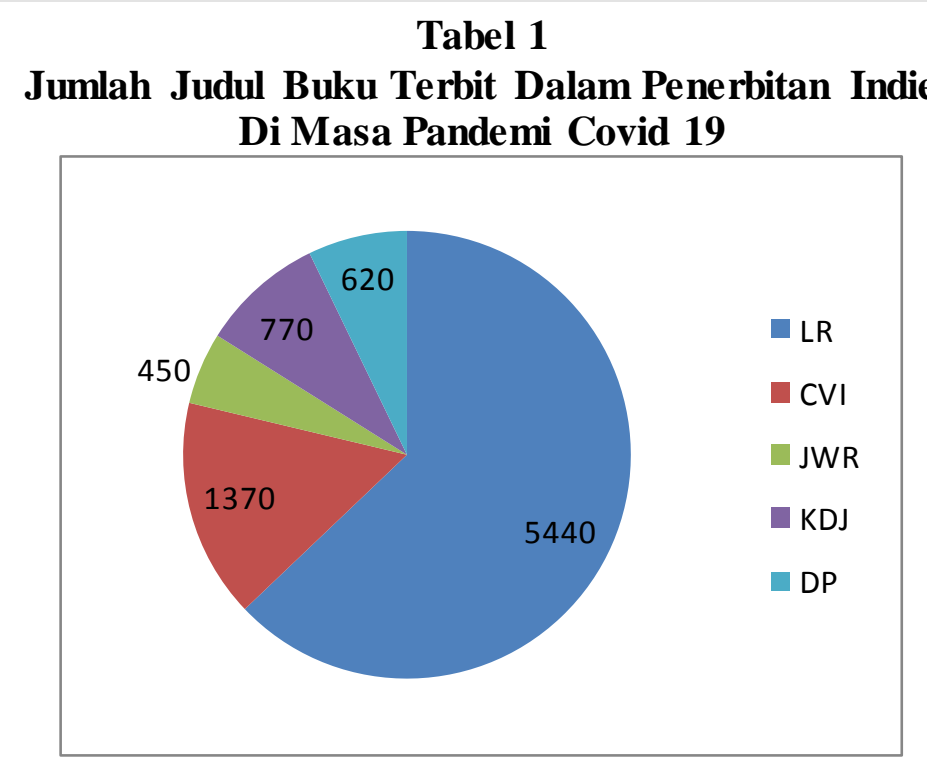

Dapat kita analisis bahwa penerbit independen LR (Cirebon, Jawa Barat) memiliki judul terbesar antara lain:

1. Memiliki mesin percetakan sendiri

2. Divisi percetakan terpisah dibawah $\mathrm{CV}$ tersendiri

3. Memiliki kantor sendiri

4. Memiliki 10-15 orang karyawan aktif yang bekerja di kantor setiap hari

Sedangkan sisanya, beroperasi secara virtual dan berdasarkan project permintaan penerbitan buku. 


\section{Tabel 2}

Jumlah Eksemplar Buku Tercetak

Di Masa Pandemi Covid 19

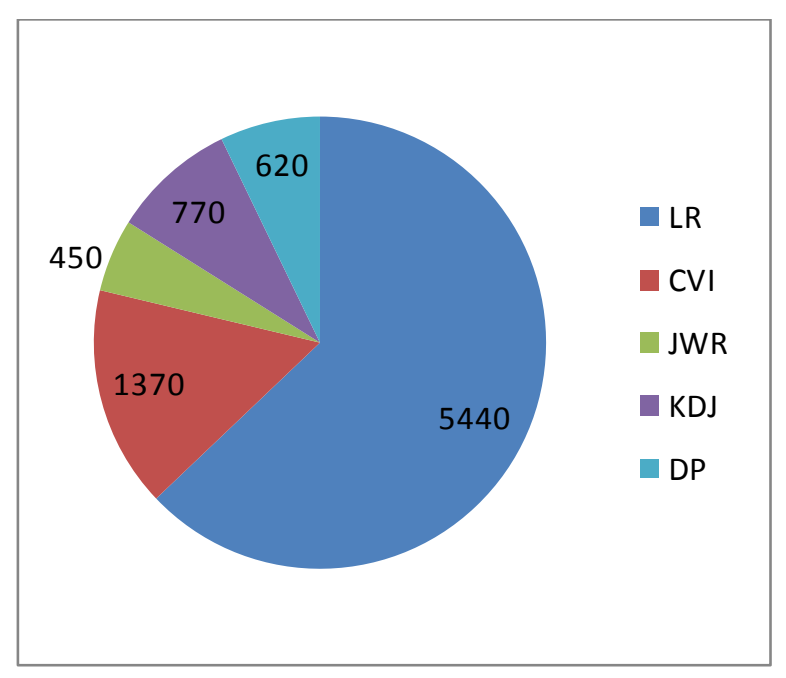

Dari data tersebut di atas, kuantitas eksemplar minimal yang tercetak memang tidak sebanyak jumlah penerbit mayor dalam sekali cetak perjudul. Namun, dalam jumlah permintaan serta distribusi, jelas menjadi pendatang baru sekaligus pesaing kuat bagi para penerbit independen.

Penerbit independen yang tadinya tidak diperhitungkan sama sekali oleh penerbit besar, kini malah menunjukan eksistensi di masa pandemi Covid 19. Hal tersebut terjadi antara lain: 


\section{Tabel 3}

\section{Perbandingan Operasional Penerbit Mayor dan Penerbit Indie}

\begin{tabular}{|c|c|c|c|}
\hline No. & Area & Penerbit Mayor & Penerbit Indie \\
\hline 1 & $\begin{array}{l}\text { Kemudahan } \\
\text { Menerbitkan } \\
\text { Buku Bagi } \\
\text { Penulis }\end{array}$ & 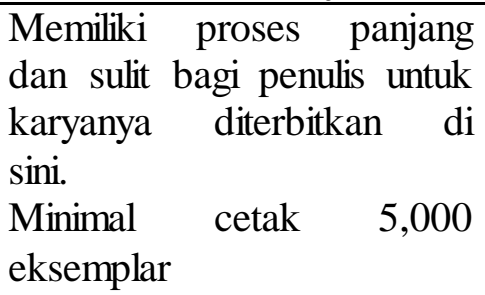 & $\begin{array}{l}\text { Proses mudah, cepat, dan tidak } \\
\text { membutuhkan dana besar. }\end{array}$ \\
\hline 2 & Promosi & Promosi lewat media sosial & $\begin{array}{l}\text { Promosi lewat media sosial } \\
\text { Mengandalkan jaringan reseller dan } \\
\text { marketer yang tidak perlu menyetok } \\
\text { buku dalam jumlah banyak }\end{array}$ \\
\hline 3 & Distribusi & $\begin{array}{l}\text { Penjualan lewat toko } \\
\text { konvensional }\end{array}$ & $\begin{array}{lll}\begin{array}{l}\text { Penjualan online langsung } \\
\text { marketer/reseller, atau market place }\end{array} \\
\end{array}$ \\
\hline
\end{tabular}

Dengan adanya PSBB dan non-aktifnya sejumlah toko retail di penerbit mayor, resikonya adalah pengangguran dari karyawan toko yang meningkat sejak pandemi Covid 2019. Berbanding terbalik dengan penerbit independen yang menciptakan lapangan kerja informal melalui kebutuhan adanya posisi:

1. Penulis, dengan jumlah tak terbatas sesuai daya kreativitas orang per-orang.

2. Editor, dibutuhkan sebanyak judul yang terbit.

3. Desain Grafis, dibutuhkan sebanyak judul yang terbit

4. Reseller \& Marketer, dibutuhkan sebanyak mungk in 
Dan juga rantai produksi dan distribusi yang tetap menghidupkan sektor lain di masa pandemi ini:

\section{Tabel 4}

\section{Proses Produksi \& Distribusi}

Penerbitan Indie

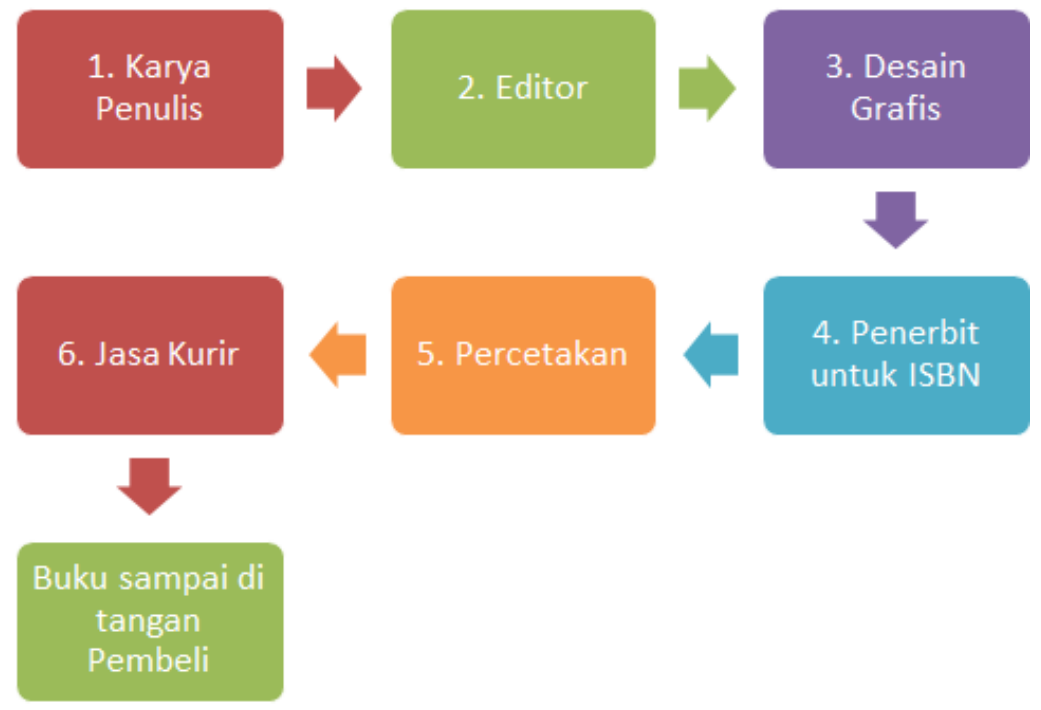

Dari tahapan tersebut di atas, penerbit indie melibatkan banyak tenaga kerja serta sektor industri lain untuk proses produksi dan distribusinya, Dengan kata lain, tetap menopang ekonomi rakyat di masa pandemi Covid 19 ini.

\section{KESIMPULAN DAN SARAN}

Beberapa hal yang penulis dapat simpulkan serta pemberiansaran, dari penelitian data sekunder ini antara lain: 
Bagi penerbit mayor:

a. Bila ingin tetap eksis di masa pandemi, penerbit mayor perlu merubah model bisnis dari yang konvensional, menjadi model bisnis online seperti penerbitan independen.

b. Penerbit mayor bisa membuka sub atau cabang penerbit dengan format produksi sama dengan penerbit independen, sehingga bisa tetap memproduksi judul buku dalam kuantitas yang relative stabil.

Bagi penerbit independen:

Selain fokus pada media cetak, penerbit independen disarankan mulai merambah ke media online, yaitu penerbitan buku berbasis aplikasi daring. Hal tersebut diharapkan mampu meningkatkan daya saing bagi penerbit independen agar tetap eksis di industri ini.

Bagi pemerintah:

Pemerintah diharapkan mampu mengadakan pelatihan dan pembinaan khususnya untuk sektor penerbitan independen, serta di sisi lain mengurangi pajak penjualan buku, agar perekonomian di sektor kreatif ini tetap produktif di masa pandemi.

Bagi penelitian selanjutnya:

Untuk penelitian selanjutnya, penulis menyarankan calon peneliti meneliti di area proses produksi, control kualitas serta penekanan pada proses pemasaran di dua kategori penerbitan ini. 


\section{DAFTAR PUSTAKA}

Muis, Afni Regita Cahyana. Ekonomi Kreatif Indonesia Dalam Perdagangan Internasional. Deepublish. 2019.

Supanah, dkk. Ekonomi Kreatif Berbasis Kearifan Lokal. 2020

Suryana. Ekonomi Kreatif. Ekonomi Baru: Mengubah Ide dan Menciptakan Peluang. Penerbit Salemba Empat. 2019.

Www.mizanstore.com

https:/www.liputan6.com/bisnis/read/4228742/headline-nasib-dunia-usaha-di-tengah-pandemicorona-siapa-bertahan-tertekan-atau-justru-tumbuh. Diakses April 2020

https:/www.kompas.com/skola/read/2021/04/19/130652969/ekonomi-kreatif-pengertian-ciriciri-faktor-pendorong-perkembangan Diakses April 2021

https://kabar24.bisnis.com/read/20201110/79/1315755/penerbit-buku-berjuang-melawan-anjloksiap-bangkit-usai-pandemi-covid-19 diakses November 2020

https://www.ikapi.org/riset/ 